\title{
Nab-paclitaxel, docetaxel, or solvent-based paclitaxel in metastatic breast cancer: a cost-utility analysis from a Chinese health care perspective
}

This article was published in the following Dove Press journal:

ClinicoEconomics and Outcomes Research

12 May 2015

Number of times this article has been viewed

\section{George Dranitsaris' \\ $\mathrm{Bo} \mathrm{Yu}^{2}$ \\ Jennifer King ${ }^{3}$ \\ Satyin Kaura ${ }^{3}$ \\ Adams Zhang ${ }^{3}$}

'Augmentium Pharma Consulting Inc., Toronto, ON, Canada; ${ }^{2}$ Fudan University Shanghai Cancer Center, Shanghai, People's Republic of China; ${ }^{3}$ Celgene Corporation, Summit, NJ, USA
Correspondence: George Dranitsaris Augmentium Pharma Consulting Inc., 283 Danforth Ave, Suite 448,

Toronto, ON, M4K IN2, Canada

Tel + I $41646 \mid 2720$

Fax + $41646 \mid 4735$

Email george@augmentium.com
Background: Paclitaxel and docetaxel are commonly used for metastatic breast cancer in the People's Republic of China. To improve the safety and efficacy of paclitaxel, an albumin-bound formulation (nab) is now available in the People's Republic of China (Abraxane ${ }^{\circledR}$ ). To provide health economic data for the key stakeholders, a cost-utility analysis comparing nab-paclitaxel to docetaxel, both as alternatives to paclitaxel, was conducted.

Methods: A meta-analysis of clinical outcomes Phase III trials comparing nab-paclitaxel (260 mg/m² every [q] 3 weeks) or branded docetaxel (100 mg/m² q 3 weeks), to solvent-based branded paclitaxel (175 mg/m² q 3 weeks) was undertaken to provide safety and clinical data. Resource use data for the delivery of anticancer therapy and for the treatment of grade $3 / 4$ toxicity was collected from a time and motion study conducted in three Chinese cancer centers and from a survey of clinicians. Using the Time Trade-Off technique, health utility estimates were derived from interviewing 28 breast cancer patients from one cancer center in the People's Republic of China. All costs were reported in 2014 US dollars.

Results: Nab-paclitaxel had the most favorable safety profile, characterized with the lowest incidence of grade 3/4 neutropenia, febrile neutropenia, anemia, and stomatitis. When the median number of cycles delivered from the clinical trials was applied, nab-paclitaxel had a cost per course of $\$ 19,752$ compared with $\$ 8,940$ and $\$ 13,741$ for paclitaxel and docetaxel, respectively. As an alternative to paclitaxel, the cost per quality-adjusted life-year (QALY) gained with nabpaclitaxel suggested better value than with docetaxel (\$57,900 vs \$130,600).

Conclusion: Nab-paclitaxel appears to be a cost-effective option compared with docetaxel and paclitaxel, for metastatic breast cancer in the People's Republic of China.

Keywords: taxanes, Abraxane, cost analysis, breast cancer, People's Republic of China

\section{Introduction}

The People's Republic of China is a culturally diverse country occupying $2 \%$ of the world's land area but supporting approximately $19 \%$ of the global population. ${ }^{1}$ With a population of 1.36 billion, it is the world's most populous country. ${ }^{2}$ Life expectancy and health in general has been steadily improving, as indicated by the steady increase of the human development index. ${ }^{2}$ However, the country faces major health care challenges, such as respiratory illnesses caused by air pollution, outbreaks of infectious diseases, as well as cancer. ${ }^{3,4}$ Cancer is a major public health concern in the People's Republic of China, with the age-standardized incidence rate being approximately 339 per 100,000 people. ${ }^{5}$ Cancer is also a major cause of death, with the age-standardized mortality being 116 per 100,000 population or almost 1.6 million deaths annually. ${ }^{5}$ The most common cause of cancer death for Chinese women is breast cancer, while malignancy of the lung predominates in men. ${ }^{5,6}$ 
Each year, there are 169,452 new breast cancer diagnoses in the People's Republic of China. ${ }^{6}$ Breast cancer is typically subdivided into three disease groups: localized (stage I or II), regional (stage III), and metastatic (stage IV). Approximately $3.3 \%$ of all newly diagnosed patients have stage IV disease, while the distribution of stages I, II, and III are $45.0 \%$, $38.2 \%$, and $13.5 \%$, respectively. ${ }^{7}$ Up to $30 \%$ of node-negative and $70 \%$ of node-positive patients with early-stage disease will also have a recurrence within 5 years. ${ }^{7,8}$ Therefore, the number of patients with metastatic breast cancer (MBC) in the People's Republic of China is substantial.

The selection of initial therapy in MBC is primarily guided by treatment given at an earlier stage of the disease. ${ }^{8}$ There are several chemotherapies used in the first-line setting, but many are taxane-based. ${ }^{3}$ Paclitaxel, docetaxel, and albumin-bound formulation (nab)-paclitaxel (Abraxane ${ }^{\circledR}$ ) are the three taxanes currently available in for $\mathrm{MBC}$ in the People's Republic of China. ${ }^{9-11}$ These agents, especially docetaxel, are associated with potentially severe side effects, such as neutropenia, anemia, and neuropathy. ${ }^{9,10}$ In addition, toxicity with agents like docetaxel is not limited to the frail and elderly, and remains a serious and occasionally lethal risk for even ostensibly fit patients. ${ }^{12}$ Furthermore, paclitaxel and docetaxel require prophylactic medication before administration, special infusion sets, and have considerable "chair time" for drug delivery. These features translate into higher treatment costs and burden on the patient. ${ }^{13,14} \mathrm{Nab}$-paclitaxel has at least comparable efficacy, a better side-effect profile than the other taxanes, a shorter infusion time than both docetaxel and paclitaxel (20 vs 60 vs 120 minutes), and does not require premedication or special infusion sets. ${ }^{11,15}$

Nab-paclitaxel is associated with several clinical and drug-delivery advantages relative to paclitaxel and docetaxel. However, it is available at a higher drug acquisition cost compared with branded paclitaxel and docetaxel. In the face of increasing health care costs, pharmacoeconomic data demonstrating value for limited resources is essential for entry into national cancer formularies. To our knowledge, such data has not been generated to identify a cost-effective taxane therapy for MBC in the People's Republic of China. To provide such data, a cost-utility analysis comparing nabpaclitaxel to docetaxel, both as alternatives to paclitaxel, was conducted from a Chinese health care perspective.

\section{Methods}

\section{Systematic review and meta-analysis}

From January 1995 to April 2014, a systematic review of PubMed, Embase, and Google Scholar was undertaken to identify published randomized Phase III trials of single nab-paclitaxel, paclitaxel, and docetaxel for the treatment of MBC. To be included in the meta-analysis, studies had to have incorporated randomization into their design and had MBC patients scheduled to receive first- or second-line chemotherapy. In addition, the doses of paclitaxel, docetaxel, or nab-paclitaxel should have been those that have received regulatory approval (175 to $210 \mathrm{mg} / \mathrm{m}^{2}$ for paclitaxel, $100 \mathrm{mg} / \mathrm{m}^{2}$ for docetaxel, and $260 \mathrm{mg} / \mathrm{m}^{2}$ for nab-paclitaxel). Once the suitable studies were identified, data extraction consisted of patient characteristics, method of drug delivery, drug dosages and schedules, number of cycles administered, incidence of grade 3/4 toxicities, number of deaths, and all disease-related clinical outcomes.

Clinical outcomes data, which consisted of response rates, grade 3/4 toxicities from the various studies were statistically merged using the method of Dersimonian and Laird to calculate a pooled mean and a 95\% confidence interval (CI) ${ }^{16}$ Equal weighting was used for combining the median progression-free survival (PFS) and overall survival (OS) because variance estimates were not provided in the selected randomized trials.

\section{Cost-consequence comparison}

A cost-consequence comparison was initially conducted. The analysis considered costs for all chemotherapy drugs, premedication, resources for preparation and administration and the management of acute side effects. Resource use data for the delivery of taxane chemotherapy was obtained from a time and motion study of 28 breast cancer patients receiving taxane treatment in three hospitals in the People's Republic of China and has been described elsewhere. ${ }^{17}$ Unit costs for the individual health care resources were obtained from the Cancer Hospital of Fu Dan University in Shanghai and from the Beijing Municipal Commission of Development and Reform. ${ }^{18}$ All costs were converted into US dollars (USD) (1 USD =6.1 RMB, as of December, 2014).

A cost-consequence table was then created to present the data, which subsequently led to the second phase of the study. In this next phase, progression-free year (PFY) and life-year (LY) gained estimates were combined with the cost data to estimate incremental cost-effectiveness ratios for nab-paclitaxel or docetaxel relative to paclitaxel.

\section{Estimating the cost impact of chemotherapy-induced toxicity}

Grade 3/4 toxicities are common occurrences in patients with advanced stage cancers receiving chemotherapy. However, there are challenges in estimating the true cost impact of these toxicities because of variability in the use of colony stimulating 
factors, alternative dosing schedules, and patient performance status. To measure the cost of these treatment-related toxicities, the incidence method developed by Hamilton and Gordon was used. ${ }^{19}$ To apply this method, the incidence $(\%)$ of the event reported in a group of patients receiving the treatment is needed along with the cost to treat the event. The percent incidence is then multiplied by the cost per event. In the current study, only side effects of sufficient magnitude, those with a minimum occurrence of $1.5 \%$ for a given drug were evaluated for cost impact. The cost of treating each side effect in the People's Republic of China was estimated from expert opinion and from a survey of treatment algorithms used in the Cancer Hospital of Fu Dan University (Fu Dan University, unpublished data, 2014).

\section{Treatment preferences and health state utilities}

Health-related quality of life with each treatment was measured in the current study, and these were presented as treatment preferences and health state utilities. The health states evaluated consisted of six cycles with docetaxel or nab-paclitaxel, both as alternatives to five cycles of paclitaxel. Within each health state, the main attributes consisted of method and schedule of drug administration, the frequency of grade 3/4 toxicities, as well as median PFS and OS. The Time Trade-Off technique was then used to measure the "healthy month" equivalence for the time spent in each health state. ${ }^{20,21}$ Scores in healthy month equivalence were then converted into quality-adjusted life-years (QALYs) by dividing the point estimates by 12 months.

The optimal sample for estimating treatment preferences and health state utilities should have been actual MBC patients who are potential candidates for taxane therapy. Given the terminal nature of $\mathrm{MBC}$, patients with early-stage disease were interviewed and were the source of health state utility data. Hence, 28 early-stage breast cancer patients from the Cancer Hospital of Fu Dan University were interviewed to measure health state utilities and treatment preferences for the three taxanes. With a sample size of 28 patients, the precision level for the health state utilities was at \pm 1.0 month, 95 times out of 100 . The study was approved by the institutional ethics review board (Fu Dan University Ethics Review Committee).

Following informed consent, the three treatments were described to each patient and this consisted of information on how each drug is delivered, how often treatment is monitored, the number of clinic visits that would be required, and the side effects to be anticipated. In the second part of the interview, the clinic data derived from the meta-analysis was presented.
This consisted on the median number of treatment cycles, the response rates, as well as median PFS and OS.

To apply the Time Trade-Off technique, patients were then asked to determine how many months of "optimal health" they thought would be equivalent to the period of time in each of the less than optimal health states previously described to them. The final estimates were used to weigh the length of time within each health state by the quality of life that a patient living through that period would experience. The final utility values derived from the interviews where then estimated by taking the ratio of the equivalent time in optimal health to the months receiving treatment with docetaxel, nab-paclitaxel, or paclitaxel (eg, 5.5 healthy months was equivalent to 15.4 months in the docetaxel scenario; hence, the health state utility would be 0.36 ). The range of the utility value would be $0-1$, with 1 being optimal health and 0 representing death.

\section{Cost-utility analysis}

A cost-utility analysis was then conducted by combining the economic, clinical, and QALY values derived using the study methodology. The incremental cost per QALY gained with docetaxel and nab-paclitaxel was the primary study outcome. This was determined by dividing the cost difference relative to paclitaxel (numerator) with the incremental number of QALYs gained (denominator). Benefits and costs were not discounted because the time intervals were short. However, a sensitivity analysis to test the stability of the baseline results was undertaken. This included reanalyzing the data using variations (ie, $\pm 10 \%$ ) in the QALY estimates, cost of drugs, and side-effects management.

\section{Results \\ Meta-analysis of randomized trials in advanced stage patients}

The study inclusion criteria were met by ten randomized Phase III trials, which evaluated single-agent paclitaxel, docetaxel, and nab-paclitaxel. Eight trials evaluated paclitaxel, docetaxel, or nab-paclitaxel in a mix of first- and second-line patients (Table 1). A paclitaxel trial also compared three doses (250 vs 210 vs $175 \mathrm{mg} / \mathrm{m}^{2}$ ) in patients receiving first- and second-line therapy. ${ }^{23}$ The arm with the higher dose was not included in the meta-analysis, as this dose has not been approved. There were also three trials evaluating single-agent docetaxel $\left(100 \mathrm{mg} / \mathrm{m}^{2}\right)$ that met the study inclusion criteria for the meta-analysis. ${ }^{10,24,25}$

Point estimates from the meta-analysis for overall tumor response, time to progression, and OS suggested that nabpaclitaxel $260 \mathrm{mg} / \mathrm{m}^{2}$ provided comparable outcomes with 
Table I Randomized trials selected for the meta-analysis

\begin{tabular}{|c|c|c|c|c|c|c|}
\hline Trial & Study arms & $\mathbf{N}$ & $\begin{array}{l}\text { Median age } \\
\text { (range) }\end{array}$ & $\begin{array}{l}\text { Overall } \\
\text { response }\end{array}$ & $\begin{array}{l}\text { Med TTP } \\
(\mathrm{mo})\end{array}$ & $\begin{array}{l}\text { Med OS } \\
(\mathrm{mo})^{\mathrm{a}}\end{array}$ \\
\hline \multirow[t]{2}{*}{ Gradishar et al"I } & $\mathrm{NP} 260 \mathrm{mg} / \mathrm{m}^{2}$ vs & 229 & $53(26-79)$ & $33 \%$ vs & 5.4 vs & I5.2 vs \\
\hline & P $175 \mathrm{mg} / \mathrm{m}^{2}$ & 225 & $53(30-83)$ & $19 \%$ & 3.9 & 13.0 \\
\hline \multirow[t]{2}{*}{ Bishop et al ${ }^{9}$} & P $200 \mathrm{mg} / \mathrm{m}^{2}$ vs & 107 & $54(36-73)$ & $29 \%$ vs & 5.3 vs & 17.3 vs \\
\hline & CMFP & 102 & $54(32-80)$ & $35 \%$ & 6.4 & 13.9 \\
\hline \multirow[t]{2}{*}{ Chan et al ${ }^{10}$} & D $100 \mathrm{mg} / \mathrm{m}^{2}$ vs & 161 & $52(32-74)$ & $48 \%$ vs & $6.1 \mathrm{vs}$ & 15 vs \\
\hline & Dox 75 mg/m² & 165 & $52(25-74)$ & $33 \%$ & 4.9 & 14 \\
\hline \multirow[t]{2}{*}{ Paridaens et $\mathrm{al}^{22}$} & $\mathrm{P} 200 \mathrm{mg} / \mathrm{m}^{2}$ & 166 & $54(31-74)$ & $25 \%$ vs & 3.9 vs & 15.6 vs \\
\hline & vs Dox $75 \mathrm{mg} / \mathrm{m}^{2}$ & 165 & $55(26-75)$ & $41 \%$ & 7.5 & $18.3^{\mathrm{b}}$ \\
\hline \multirow[t]{3}{*}{ Sledge et $\mathrm{al}^{24}$} & P $175 \mathrm{mg} / \mathrm{m}^{2}$ vs & 229 & $56(27-76)$ & $34.0 \%$ vs & $6.3 \mathrm{vs}$ & 22.5 vs \\
\hline & Dox $60 \mathrm{mg} / \mathrm{m}^{2}$ vs & 224 & $58(25-79)$ & $36 \%$ vs & 6.0 vs & $19.1^{\mathrm{b}} \mathrm{vs}$ \\
\hline & $\mathrm{P} I 75$ + Dox $50 \mathrm{mg} / \mathrm{m}^{2}$ & 230 & $56(27-78)$ & $47 \%$ & 8.2 & 22.4 \\
\hline \multirow[t]{2}{*}{ Jones et $\mathrm{a}^{25}$} & D $100 \mathrm{mg} / \mathrm{m}^{2}$ vs & 225 & $56(22-93)$ & $32.0 \%$ vs & 5.7 vs & I5.4 vs \\
\hline & P $175 \mathrm{mg} / \mathrm{m}^{2}$ & 224 & $54(28-82)$ & $25.0 \%$ & 3.6 & 12.7 \\
\hline \multirow[t]{3}{*}{ Winer et $\mathrm{al}^{23}$} & P $175 \mathrm{mg} / \mathrm{m}^{2}$ vs & 158 & NR & $21.5 \%$ vs & 4.0 vs & $11.3 \mathrm{vs}$ \\
\hline & P $210 \mathrm{mg} / \mathrm{m}^{2}$ vs & 156 & NR & $25.0 \%$ vs & 4.1 vs & $11.9 \mathrm{vs}$ \\
\hline & P $250 \mathrm{mg} / \mathrm{m}^{2}$ & 155 & $\mathrm{NR}$ & $20.0 \%$ & 4.9 & 13.8 \\
\hline \multirow[t]{2}{*}{ Bonneterre et $\mathrm{a}^{26}$} & D $100 \mathrm{mg} / \mathrm{m}^{2}$ vs & 86 & 55 (28-79) & $43 \%$ vs & 6.5 vs & 16.0 vs \\
\hline & $\mathrm{V}-5 \mathrm{FU}$ & 90 & $55(32-74)$ & $38.8 \%$ & 5.1 & $15.0^{\mathrm{a}}$ \\
\hline \multirow[t]{2}{*}{ Di Leo et $\mathrm{al}^{27}$} & P 175 mg/m² vs & 288 & $52(25-78)$ & $25.3 \%$ vs & 5.2 vs & 19.9 vs \\
\hline & $\mathrm{P} \mid 75 \mathrm{mg} / \mathrm{m}^{2}+\mathrm{L}$ & 291 & $51(23-87)$ & $35.1 \%$ & 6.6 & 22.7 \\
\hline \multirow[t]{2}{*}{ Albain et $\mathrm{a}^{28}$} & P $175 \mathrm{mg} / \mathrm{m}^{2}$ vs & 263 & $53(27-75)$ & $26.2 \%$ vs & 4.0 vs & 15.8 vs \\
\hline & $P \mid 75 \mathrm{mg} / \mathrm{m}^{2}+\mathrm{G}$ & 266 & $53(26-83)$ & $41.4 \%$ & 6.1 & 18.6 \\
\hline
\end{tabular}

Notes: ${ }^{a}$ Overall survival for patients being treated in either the first- or second-line setting; ${ }^{b}$ crossover into the alternative treatment arm was part of the trial protocol. Abbreviations: 5FU, 5-fluorouracil; CMFP, cyclophosphamide/methotrexate/fluorouracil/prednisone; D, docetaxel; Dox, doxorubicin; G, gemcitabine; L, lapatinib; Med, median; NP, nab-paclitaxel; NR, not reported; OS, overall survival; P, paclitaxel; TTP, time to progression; V, vinorelbine; mo, months; vs, versus.

docetaxel at $100 \mathrm{mg} / \mathrm{m}^{2}$ (33.2\% vs $40.6 \% ; 5.4$ vs 6.1 months; and 15.2 vs 15.4 months, respectively), but incremental benefits were noted relative to paclitaxel (33.2\% vs $25.3 \% ; 5.4$ vs 3.9 months; and 15.2 vs 14.3 months, respectively). The statistically pooled point estimates for each of the major grade $3 / 4$ toxicities are presented in Table 2. It appeared that nab-paclitaxel had the most favorable toxicity profile, with

Table 2 Pooled grade 3/4 toxicity rates with taxane therapy in metastatic breast cancer ${ }^{a}$

\begin{tabular}{llll}
\hline Grade 3/4 event & $\begin{array}{l}\text { Paclitaxel } \\
\text { (\%) }\end{array}$ & $\begin{array}{l}\text { Docetaxel } \\
\text { (\%) }\end{array}$ & $\begin{array}{l}\text { Nab-paclitaxel } \\
\text { (\%) }\end{array}$ \\
\hline Neutropenia & 42.6 & 86.9 & 30.0 \\
Febrile neutropenia & 1.8 & 10.0 & 1.8 \\
Anemia & 5.1 & 5.5 & 1.0 \\
Thrombocytopenia & 1.8 & 2.1 & $<1.0$ \\
Emesis & 1.9 & 6.6 & $<1.0$ \\
Stomatitis & 1.0 & 6.7 & $<1.0$ \\
Diarrhea & 1.1 & 7.2 & 0.0 \\
Neurotoxicity & 7.3 & 7.0 & 10.0 \\
Edema & 0.0 & 5.2 & 0.0 \\
Rash & 0.0 & 1.5 & 0.0 \\
Hypersensitivity reaction & 2.0 & 2.5 & 0.0 \\
Treatment-related death & 0.7 & 1.4 & 0.0 \\
\hline
\end{tabular}

Note: ${ }^{\mathrm{T}}$ These are the point estimates for each side effect that were estimated from the statistical pooling of trial reported grade $3 / 4$ toxicities. the lowest rates for neutropenia, anemia, thrombocytopenia, hypersensitivity reaction, and treatment-related death (Table 2).

\section{Measuring the cost impact of grade 3/4 toxicity}

The side effects that were the most prominent with taxane therapy were neutropenia, febrile neutropenia, anemia, diarrhea, stomatitis, emesis, edema, and neurotoxicity (Table 2 ). To apply the incidence method, the estimated cost to manage each toxic event was multiplied with the incidence rates estimated from the statistical analysis. The cost impact of each toxicity was combined and then added to the cost per course of therapy (Table 3 ).

\section{Cost comparison}

A cost comparison table highlighting the cost and benefits of docetaxel, nab-paclitaxel, and paclitaxel was then constructed. The clinical data suggested that nab-paclitaxel (260 mg/m $/ \mathrm{m}^{2}$ q 3 weeks) provides similar objective tumor responses and PFS to docetaxel. In contrast, nab-paclitaxel appears to be superior to paclitaxel in these two clinical end points. From an economic perspective in the People's Republic 
Table 3 Cost of treating selected grade 3/4 toxicities in cancer patients

\begin{tabular}{|c|c|c|}
\hline Grade $3 / 4$ event & Medical intervention & $\begin{array}{l}\text { Cost per } \\
\text { event }(\$)^{a, b}\end{array}$ \\
\hline Neutropenia & Dose reduction or treatment delay & 0.00 \\
\hline Febrile neutropenia & Hospital admission with IV antibiotics & 621 \\
\hline Anemia & $\begin{array}{l}\text { Red cell transfusions in } 43 \% \text { of } \\
\text { patients, colony stimulating } \\
\text { factors in } 33 \%\end{array}$ & 913 \\
\hline Thrombocytopenia & Platelet transfusions & 155 \\
\hline Emesis & $\begin{array}{l}\text { Rescue with } 5 \mathrm{HT} 3 \text { antiemetics } \\
\text { and steroids }\end{array}$ & 81 \\
\hline Stomatitis & $\begin{array}{l}\text { Supportive care of symptoms, } \\
\text { hydration if required }\end{array}$ & 5.0 \\
\hline Diarrhea & $\begin{array}{l}\text { Oral antidiarrheals, octreotide, } \\
\text { and hydration if required }\end{array}$ & 602 \\
\hline Neurotoxicity & Supportive care of symptoms & 7.0 \\
\hline Edema & $\begin{array}{l}3 \text { days of dexamethasone }+ \\
\text { prochlorperazine as needed }\end{array}$ & 11.0 \\
\hline
\end{tabular}

Notes: ${ }^{2}$ The costs to treat each event were determined from expert opinion and from treatment algorithms of the Cancer Hospital of Fu Dan University; ball costs were converted into 2014 US dollars and were obtained from the Cancer Hospital of Fu Dan University and from the Beijing Municipal Commission of Development and Reform. ${ }^{18}$ Abbreviation: IV, intravenous.

of China, nab-paclitaxel had the highest drug cost per cycle and per course among the three agents (Table 4). However, nabpaclitaxel had the most favorable safety profile, which translated into lower costs for side-effects management (Table 4)

When the cost of treating side effects was added to the overall cost per course, nab-paclitaxel remained the highest-cost regimen. Standard branded paclitaxel would be the least costly agent for the treatment of $\mathrm{MBC}$ in the People's Republic of China. Notwithstanding, for an accurate measure of cost effectiveness, the incremental cost of both nab-paclitaxel and docetaxel relative to paclitaxel has to be weighed against the difference in PFS, OS, and qualityadjusted survival benefit.

\section{Cost-effectiveness analysis}

The analysis was continued with a cost-effectiveness analysis, with the intent of estimating the incremental cost per PFY and LY with nab-paclitaxel or docetaxel, when each agent was used as an alternative to paclitaxel (Table 5). Docetaxel had an overall cost of $\$ 26,200$ per PFY gained compared with $\$ 86,500$ for nab-paclitaxel. When the analysis was extended to include differences in OS, the cost per LY gained with docetaxel and nab-paclitaxel were reduced to $\$ 24,000$ and $\$ 58,900$, respectively. These findings imply that in the Chinese health care setting, docetaxel is less costly per LY gained than is nab-paclitaxel, when both agents are used as alternatives to standard branded paclitaxel. However, it is important to point out that these calculations do not as yet consider the utility differences associated with each agent.

\section{Treatment preferences and health state utilities}

Treatment preferences and health state utilities for each alternative were provided by interviewing 28 breast cancer patients with early-stage disease. Patients had a mean of 50 years (range 31-72 years), and 22 of 28 (78.6\%) had previously received chemotherapy. In addition, 18 of 28

Table 4 Nab-paclitaxel, paclitaxel, and docetaxel in metastatic breast cancer: a cost-consequence comparison

\begin{tabular}{|c|c|c|c|}
\hline Components $(95 \% \mathrm{CI})$ & Paclitaxel & Docetaxel & Nab-paclitaxel \\
\hline \multicolumn{4}{|l|}{ Clinical data } \\
\hline Dosage & $175-200 \mathrm{mg} / \mathrm{m}^{2} \mathrm{q} 3 \mathrm{wks}$ & $100 \mathrm{mg} / \mathrm{m}^{2} \mathrm{q} 3 \mathrm{wks}$ & $260 \mathrm{mg} / \mathrm{m}^{2} \mathrm{q} 3 \mathrm{wks}$ \\
\hline Duration of infusion & 3 hours & I hour & 20 minutes \\
\hline Median number of cycles & 5 & 6 & 6 \\
\hline Overall response & $25.3 \%(22.4 \%-28.2 \%)$ & $40.6 \%(30.1 \%-51.2 \%)$ & $33.2 \%(27.1 \%-39.3 \%)$ \\
\hline Median progression-free survival & 3.9 months & 6.1 months & 5.4 months \\
\hline Median overall survival & 13 months & 15.4 months & 15.2 months \\
\hline \multicolumn{4}{|l|}{ Economic data } \\
\hline Drug cost per cycle & $\$ 1,520$ & $\$ 2,104$ & $\$ 3,230^{\mathrm{a}}$ \\
\hline $\begin{array}{l}\text { Preparation, administration, and } \\
\text { premedication cost per cycle }{ }^{\mathrm{a}}\end{array}$ & $\$ 254.14$ & $\$ 158.52$ & $\$ 58.57$ \\
\hline Total cost per cycle & $\$ 1,774$ & $\$ 2,263$ & $\$ 3,289$ \\
\hline Total cost per course ${ }^{\mathrm{b}}$ & $\$ 8,87$ I & $\$ 13,575$ & $\$ 19,73 \mid$ \\
\hline Overall cost impact of side effects ${ }^{c}$ & $\$ 69.29$ & $\$ 165.93$ & $\$ 21.04$ \\
\hline Overall cost per course ${ }^{d}$ & $\$ 8,940$ & $\$|3,74|$ & $\$ 19,752$ \\
\hline
\end{tabular}

Notes: abtained from a time and motion study of 28 breast cancer patients treated in the People's Republic of China; ${ }^{b}$ the cost per cycle was multiplied by the median number of cycles administered; cthe \% incidence of each side effect in Table 2 was multiplied by the cost per event in Table 3; ${ }^{d}$ the cost impact of side effects was added to the total cost per course.

Abbreviations: $\mathrm{Cl}$, confidence interval; q, every; wks, weeks. 
Table 5 Cost-effectiveness and -utility analysis of taxane therapies in metastatic breast cancer

\begin{tabular}{|c|c|c|}
\hline $\begin{array}{l}\text { Economic } \\
\text { outcomes }\end{array}$ & $\begin{array}{l}\text { Nab-paclitaxel } \\
(95 \% \mathrm{Cl})\end{array}$ & $\begin{array}{l}\text { Docetaxel } \\
(95 \% \mathrm{Cl})\end{array}$ \\
\hline \multicolumn{3}{|c|}{ Cost-effectiveness analysis ${ }^{\mathrm{a}, \mathrm{b}}$} \\
\hline $\begin{array}{l}\text { Cost per PFY gained } \\
\text { (vs paclitaxel) }\end{array}$ & $\$ 86,500$ & $\$ 26,200$ \\
\hline $\begin{array}{l}\text { Cost per LY gained } \\
\text { (vs paclitaxel) }\end{array}$ & $\$ 58,900$ & $\$ 24,000$ \\
\hline \multicolumn{3}{|l|}{ Cost-utility analysis ${ }^{\mathrm{a}, \mathrm{b}}$} \\
\hline Quality-adjusted & 0.19 & 0.037 \\
\hline life-years gained & $(0.13$ to 0.25$)$ & $(-0.012$ to 0.086$)$ \\
\hline $\begin{array}{l}\text { Cost per QALY } \\
\text { gained }^{c, d}\end{array}$ & $\begin{array}{l}\$ 57,900(\$ 38,200 \text { to } \\
\$ 128,800)\end{array}$ & $\begin{array}{l}\$ 130,600(\$ 35,700 \text { to } \\
\text { dominated) }\end{array}$ \\
\hline
\end{tabular}

Notes: 'Rounded to the nearest hundred; 'belative to paclitaxel; 'incremental cost of nab-paclitaxel and docetaxel was divided by the gain in QALYs; ${ }^{9} 95 \% \mathrm{Cl}$ limits were estimated using the $95 \% \mathrm{Cl}$ limits for the difference in the healthy month equivalent (ie, in the denominator), while keeping the cost differences relative to paclitaxel (ie, in the numerator) constant; edominated means that docetaxel is more costly and does not provide more benefit in terms of QALYs gained than paclitaxel.

Abbreviations: Cl, confidence interval; LY, life-year; PFY, progression-free year; QALY, quality-adjusted life-year.

(64.3\%) had prior taxane experience. Of these 18, 14, three, and one had received docetaxel, paclitaxel, and nab-paclitaxel respectively. Of the 22 patients who had previously received chemotherapy, 20 (71.4\%) had experienced acute toxicity with their treatment.

Following the presentation of all background clinical data on each regimen, patients were asked to select which drug they would like to receive if their disease became metastatic. Twenty-two of 28 (78.6\%) patients selected nab-paclitaxel as their treatment of choice. Only six of 28 (21.4\%) chose docetaxel as their first choice and none selected paclitaxel. The healthy month equivalence scores were then converted into utilities, which were between 0 and 1, with the extremes being death and ideal health. The results indicated that nabpaclitaxel had a utility score of 0.63 compared with 0.57 and 0.51 for paclitaxel and docetaxel, respectively. Nabpaclitaxel also had the largest increment in healthy month equivalence scores compared with paclitaxel (2.24 months or 0.19 [95\% CI: 0.13 to 0.25 ] QALYs gained). However, the increment in healthy month equivalence scores with docetaxel relative to paclitaxel was more modest, with a gain of only 0.44 months, which is equivalent to 0.037 QALYs (Table 5).

\section{Cost-utility analysis}

One of the limitations in estimating the cost per LY gained in the current study is that it does not incorporate differences in utilities between the three treatments. Therefore, a cost-utility analysis was undertaken where the additional cost of nab-paclitaxel $(\$ 10,812)$ was divided by the 0.19
QALY gain (an additional 2.24 health months equivalence, equal to a QALY gain of 2.24 months/12 months). The results suggested that nab-paclitaxel would be associated with incremental cost of approximately $\$ 57,900$, per QALY gained (95\% CI: $\$ 38,200$ to $\$ 128,800)$ relative to paclitaxel. However, the cost per QALY gained with docetaxel would be substantially higher, at $\$ 130,600$, to being economically dominated by paclitaxel (Table 5). A finding of economic dominance suggests that docetaxel is more costly and does not provide added benefit (ie, QALYs) when used as an alternative to paclitaxel. In contrast, nab-paclitaxel appears to be cost effective relative to paclitaxel.

\section{Sensitivity analysis on the incremental cost per QALY gained}

A series of one-way sensitivity analyses were conducted to evaluate the stability of the initial cost per QALY-gained outcomes. This consisted of varying the number of QALYs gained for nab-paclitaxel and docetaxel, the drug acquisition cost of paclitaxel and docetaxel, as well as the cost of side effects and the overall cost per course for these agents by $\pm 10 \%$. The results were, for the most part, stable and only modestly susceptible to the paclitaxel and docetaxel drug cost. When the cost of paclitaxel was reduced by $10 \%$, the cost per QALY gained for nab-paclitaxel and docetaxel increased to $\$ 61,900$ and $\$ 151,400$, respectively. Even a doubling the cost of side-effects management had only a marginal effect on the final cost per QALY estimates.

\section{Discussion}

A comprehensive economic analysis was undertaken from a Chinese health care perspective to evaluate overall health care resource use for the three taxanes available for $\mathrm{MBC}$ in the People's Republic of China. The analysis was then extended into a cost-effectiveness analysis, which initially estimated the cost per PFY and cost per LY gained with nab-paclitaxel or docetaxel, both as alternatives to paclitaxel. The findings suggested that both nab-paclitaxel and docetaxel would be associated with higher costs than paclitaxel per PFY and LY gained. When differences in health state utilities were incorporated into the analysis, the incremental cost per QALY gained became favorable for nab-paclitaxel over docetaxel, when both were considered as alternatives to standard branded paclitaxel.

The meta-analysis of randomized comparative trials also indicated that nab-paclitaxel has the most favorable toxicity profile among the three agents. In addition, a recent time and motion study conducted in the People's Republic of China 
revealed that nab-paclitaxel had a significant impact on reducing materials, supplies, personnel, and, most important for the patient, total chair time for drug delivery. ${ }^{17}$ Combining all of these attributes should make nab-paclitaxel the preferred therapy, at least from the patient's perspective. The results from our preference assessment support this hypothesis. Overall, 22 of 28 (78.6\%) patients selected nab-paclitaxel as their taxane of choice. These findings are consistent with other preference studies and are relevant because our sample consisted of early-stage breast cancer patients who may be future candidates for taxane therapy. ${ }^{29}$

In the current study, the cost per QALY gained with nab-paclitaxel and docetaxel were estimated to be approximately $\$ 58,000$ and $\$ 131,000$, respectively, when used as an alternative to paclitaxel. The value of estimating such cost per QALY gained ratios is that they allow a comparison of drugs within and across therapeutic areas. As an illustration, the incremental cost per QALY gained in the United States when bevacizumab is added to first-line paclitaxel in patients with $\mathrm{MBC}$ is cost ineffective, at $\$ 745,000$ per QALY gained. ${ }^{30}$ Similarly, the addition of bevacizumab to standard chemotherapy for patients with advanced ovarian cancer has a cost of approximately $\$ 2.4$ million per QALY. ${ }^{31}$ However, such ratios should not be compared across countries because of differences in health care systems and thresholds for economic value. In the People's Republic of China, cost per QALY thresholds for drug-formulary decision making have not been established. Therefore, local regions will need to consider the cost per QALY estimates determined for the three taxanes in this study and make a value-based decision that meets the needs of their patients and their annual cancer drug budgets.

There are a limited number of breast cancer cost-utility studies conducted in the People's Republic of China, making intracountry comparisons across different treatments difficult. ${ }^{32}$ Nevertheless, cost-utility studies should be encouraged in the People's Republic of China because they would better inform drug policy decision making. To our knowledge, this is first such study in MBC patients to be undertaken in the People's Republic of China, and we encourage other investigators to conduct similar investigations in order to develop a value database for cancer drugs.

There are a number of limitations in the current economic analysis that have to be addressed. We had to rely on cross-trial comparisons for the relevant clinical and safety outcomes because there were no head-to-head comparative studies evaluating each of the three agents. However, a randomized Phase II trial in the first-line setting did confirm that nab-paclitaxel had a lower incidence dose-limiting toxicities than did docetaxel. ${ }^{15}$ Nevertheless, cross-trial comparisons are associated with potential biases, especially in comparing toxicity differences and OS gains. There was only one trial comparing nab-paclitaxel to paclitaxel. In estimating the cost per course, the median number of cycles delivered in the clinical trials was used instead of the mean because the latter was not reported. The OS differences between nab-paclitaxel and paclitaxel, as reported in the pivotal randomized trial, was used in the cost-effectiveness analysis. ${ }^{11}$ However, the difference in OS did not reach statistical significance. This is not uncommon in trials of anticancer agents and may be due to less than optimal statistical power and the impact of secondary therapies.

\section{Conclusion}

In summary, the findings of the economic evaluation indicated nab-paclitaxel would be a cost-effective alternative to docetaxel as initial therapy in $\mathrm{MBC}$, from the Chinese health care perspective, and would be most preferred by patients. When used in place of paclitaxel, key stakeholders in the People's Republic of China must make a value judgment, as it relates to a cost per QALY gained of approximately $\$ 58,000$. Relative to other anticancer agents that have received reimbursement in Europe and the United States, this seems to be a reasonable proposition.

\section{Acknowledgments}

Celgene Corporation provided financial support to conduct this study. The corresponding author had full access to the data in the study and had the final responsibility for the decision to submit the paper. The abstract of this paper was presented as a poster presentation at the 17th annual European Congress of the International Society of Pharmacoeconomics and at the Outcomes Research of the 14th San Antonio Breast Cancer Symposium. The poster abstract was published in Value in Health.

\section{Disclosure}

JK, SK, and AZ are employees of Celgene Corporation. The authors report no other conflicts of interest in this work.

\section{References}

1. Nationmaster: China People Stats. Available from: http://www. nationmaster.com/country-info/profiles/China/People. Accessed April 13, 2015

2. hdr.undp.org/[homepage on the Internet]. United Nations Human Development Reports: Media. United Nations Development Programme; 2015 [cited May 22, 2014]. Available from: http://hdr.undp.org/en/media/ Lets-Talk-HD-HDI_2010.pdf. Accessed April 26, 2015. 
3. Guo Y, Li S, Tian Z, Pan X, Zhang J, Williams G. The burden of air pollution on years of life lost in Beijing, China, 2004-2008: retrospective regression analysis of daily deaths. BMJ. 2013;347:f7139.

4. Zheng W, McLerran DF, Rolland BA, et al. Burden of total and cause-specific mortality related to tobacco smoking among adults aged $\geq 45$ years in Asia: a pooled analysis of 21 cohorts. PLoS Med. 2014;11(4):e1001631.

5. Chen W, Zheng R, Zhang S, et al. Report of incidence and mortality in China cancer registries, 2009. Chin J Cancer Res. 2013;25(1):10-21.

6. Wang YC, Wei LJ, Liu JT, Li SX, Wang QS. Comparison of Cancer Incidence between China and the USA. Cancer Biol Med. 2012;9(2):128-132.

7. Canadian Cancer Society/National Cancer Institute of Canada. Canadian Cancer Statistics 2008. Toronto, ON: Canadian Cancer Society; 2008. Available from: https://www.cancer.ca/ /media/cancer.ca/ CW/cancer\%20information/cancer\%20101/Canadian\%20 cancer\%20 statistics/Canadian-Cancer-Statistics-2008-EN.pdf. Accessed May 15, 2014.

8. Cardoso F, Harbeck N, Fallowfield L, Kyriakides S, Senkus E; ESMO Guidelines Working Group. Locally recurrent or metastatic breast cancer: ESMO Clinical Practice Guidelines for diagnosis, treatment and follow-up. Ann Oncol. 2012;23 Suppl 7:vii11- vii19.

9. Bishop JF, Dewar J, Toner GC, et al. Initial paclitaxel improves outcome compared with CMFP combination chemotherapy as frontline therapy in untreated metastatic breast cancer. $J$ Clin Oncol. 1999; 17(8):2355-2364.

10. Chan S, Friedrichs K, Noel D, et al; 303 Study Group. Prospective randomized trial of docetaxel versus doxorubicin in patients with metastatic breast cancer. J Clin Oncol. 1999;17(8):2341-2354.

11. Gradishar WJ, Tjulandin S, Davidson N, Shaw H, Desai N, Bhar P, et al. Phase III trial of nanoparticle albumin-bound paclitaxel compared with polyethylated castor oil-based paclitaxel in women with breast cancer. J Clin Oncol. 2005;23(31):7794-7803

12. Bradbury J. Docetataxel downside highlighted. Lancet Oncology. 2005;6(7):447.

13. Leung PP, Tannock IF, Oza AM, Puodziunas A, Dranitsaris G. Cost-utility analysis of chemotherapy using paclitaxel, docetaxel, or vinorelbine for patients with anthracycline-resistant breast cancer. J Clin Oncol. 1999;17(10):3082-3090.

14. Li N, van Agthoven M, Willemse P, Uyl-de Groot C. A cost - utility analysis comparing second-line chemotherapy schemes in patients with metastatic breast cancer. Anticancer Drugs. 2001;12(6):533-540.

15. Gradishar WJ, Krasnojon D, Cheporov S, et al. Phase II trial of nabpaclitaxel compared with docetaxel as first-line chemotherapy in patients with metastatic breast cancer: final analysis of overall survival. Clin Breast Cancer. 2012;12(5):313-321.

16. DerSimonian R, Laird N. Meta-analysis in clinical trials. Control Clin Trials. 1986;7(3):177-188.

17. Dranitsaris G, Yu B, Wang L, et al. Abraxane ${ }^{\circledR}$ versus Taxol ${ }^{\circledR}$ for patients with advanced breast cancer: A prospective time and motion analysis from a Chinese health care perspective. J Oncol Pharm Pract. Epub October 14, 2014.
18. service2.bjpc.gov.cn [homepage on the Internet]. Beijing Municipal Commission of Development and Reform; [cited January 9, 2014]. Available from: http://service2.bjpc.gov.cn/bjpc/mediprice/ MedicalService2.jsp). Accessed April 26, 2015.

19. Hamilton RA, Gordon T. Incidence and cost of hospital admissions secondary to drug interactions involving theophylline. Ann Pharmacother. 1992;26(12):1507-1511.

20. Torrance GW. Utility approach to measuring health-related quality of life. J Chronic Dis. 1987;40(6):593-603.

21. Gafni A. Alternatives to the QALY measure for economic evaluations. Support Care Cancer. 1997;5(2):105-111.

22. Paridaens R, Biganzoli L, Bruning P, et al. Paclitaxel versus doxorubicin as first-line single-agent chemotherapy for metastatic breast cancer: a European Organization for Research and Treatment of Cancer Randomized Study with cross-over. J Clin Oncol. 2000;18(4):724-733.

23. Winer EP, Berry DA, Woolf S, et al. Failure of higher-dose paclitaxel to improve outcome in patients with metastatic breast cancer: cancer and leukemia group B trial 9342. J Clin Oncol. 2004;22(11):2061-2068.

24. Sledge GW, Neuberg D, Bernardo P, et al. Phase III trial of doxorubicin, paclitaxel, and the combination of doxorubicin and paclitaxel as front-line chemotherapy for metastatic breast cancer: an intergroup trial (E1193). J Clin Oncol. 2003;21(4):588-592.

25. Jones SE, Erban J, Overmoyer B, et al. Randomized phase III study of docetaxel compared with paclitaxel in metastatic breast cancer. J Clin Oncol. 2005;23(24):5542-5551.

26. Bonneterre J, Roché H, Monnier A, et al. Docetaxel vs 5-fluorouracil plus vinorelbine in metastatic breast cancer after anthracycline therapy failure. Br J Cancer. 2002;87(11):1210-1215.

27. Di Leo A, Gomez HL, Aziz Z, et al. Phase III, double-blind, randomized study comparing lapatinib plus paclitaxel with placebo plus paclitaxel as first-line treatment for metastatic breast cancer. J Clin Oncol. 2008;26(34):5544-5552.

28. Albain KS, Nag SM, Calderillo-Ruiz G, et al. Gemcitabine plus paclitaxel versus paclitaxel monotherapy in patients with metastatic breast cancer and prior anthracycline treatment. J Clin Oncol. 2008;26(24):3950-3957.

29. Dranitsaris G, Cottrell W, Spirovski B, Hopkins S. Economic analysis of albumin-bound paclitaxel for the treatment of metastatic breast cancer. J Oncol Pharm Pract. 2009;15(2):67-78.

30. Montero AJ, Avancha K, Glück S, Lopes G. A cost-benefit analysis of bevacizumab in combination with paclitaxel in the first-line treatment of patients with metastatic breast cancer. Breast Cancer Res Treat. 2012;132(2):747-751.

31. Mehta DA, Hay JW. Cost-effectiveness of adding bevacizumab to first line therapy for patients with advanced ovarian cancer. Gynecol Oncol. 2014;132(3):677-683.

32. research.tufts-nemc.org [homepage on the Internet]. CEA registry: Who is CEVR? Tufts Medical Center; 2013 [cited May 28, 2014]. Available from: https://research.tufts-nemc.org/cear4/AboutUs/WhoisCEVR. aspx. Accessed April 26, 2015.
ClinicoEconomics and Outcomes Research

\section{Publish your work in this journal}

ClinicoEconomics \& Outcomes Research is an international, peerreviewed open-access journal focusing on Health Technology Assessment, Pharmacoeconomics and Outcomes Research in the areas of diagnosis, medical devices, and clinical, surgical and pharmacological intervention. The economic impact of health policy and health systems

\section{Dovepress}

organization also constitute important areas of coverage. The manuscript management system is completely online and includes a very quick and fair peer-review system, which is all easy to use. Visit http://www.dovepress.com/testimonials.php to read real quotes from published authors. 